\title{
The importance of diagnostic testing
}

\begin{abstract}
Today antibiotic resistance, flesh-eating bacteria and chronic illnesses plague both the human and animal worlds. This brief communication is intended to highlight the importance of diagnostic medicine in early detection and identification of specific disease pathogens and other etiologies so that targeted treatments can be instilled. Definitively-diagnosed disease-directed therapy leads to more rapid resolve of clinical illness and makes it less likely that chronic ailments will continue to develop.
\end{abstract}

Keywords: veterinary, diagnostic medicine, blood work, clinical pathology, diagnostic tools
Volume 3 Issue 4 - 2016

\author{
Athema Etzioni \\ Department of Pathobiology, Tuskegee University College of \\ Veterinary Medicine, USA \\ Correspondence: Athema Etzioni, Department of \\ Pathobiology, Tuskegee University College of Veterinary \\ Medicine, USA, 1200 Old Montgomery Road, Tuskegee, AL \\ 36088, USA, Tel (334)724 4I05, Fax (334) 724 4I I0, (352) 870 \\ 4108,Email aetzioni@mytu.tuskegee.edu
}

Received: June 07, 2016 | Published: June 15, 2016

\section{Opinion}

As a Veterinary Clinical Pathologist and Clinical Practitioner, diagnostic medicine has always been a big part of the plan. The plan to determine the next step in figuring out what the patient is primarily ailing with? What is the patient lacking or what does she/he have too much of? Sometimes the problem may be easy to identify grossly, as is the case with skin abrasions, complete fractures of long bones, and missing body parts (e.g., cropped tails, removed digits, puncture wounds, etc.), cataracts and nuclear sclerosis in older pets. However, sometimes we need the aid of diagnostic tools to better pinpoint where the main problem is. That way focused medicine and client education can be implemented. In other cases where diagnostics are not used, empirical treatment may suffice. However, running the diagnostic tests first may allow us to find out sooner the exact issue so that focused therapy can quickly get the problem resolved. The use of the many diagnostic tools to assure we are treating the patient with the necessary medications to curb their illness is just one part of being a competent veterinarian or human doctor as well. Hematology and clinical chemistry analyzers, the use of the light microscope to evaluate fecal and urinalysis samples and the development of various "SNAP TESTS" to determine if an animal is ailing with common or sometime uncommon diseases is a must. ${ }^{1}$ Often individuals may become so familiar with certain disease presentations in patients that the diagnostics may be foregone.

It is engrained in me to ask where is the blood work? In human medicine, the patient is able to communicate vital information to the practitioner to aid in determining what treatments should be implemented. ${ }^{2,3}$ However, in veterinary medicine the client may give us this vital information, but still the diagnostic testing is of the utmost importance to really get to the root of the problem. Oh so often large animal practitioners may not perform blood work and so some of the great cases that our large animals ail with are treated empirically. One may recognize when there is a displaced abomasum, "downer cow" or goat with bloat. Perhaps the clinical signs are classic in a horse with colic. Whatever the illness, be encouraged to find the definitive diagnosis, which is often decided after performing few or many diagnostic tests. Go that extra step and educate the client on the reasons why diagnostic testing is necessary. When a patient with an infection, whether internal or external, is treated empirically with an antibiotic and the wound does not heal, it decreases the ability of culture to find the culprit. Now we have the development of Methicillin-Resistant Staphylococcus aureus (MRSA) and flesh-eating bacteria. ${ }^{4-9}$ Culture and sensitivity should be performed first and then antibiotics may be implemented until the results of this vital diagnostic tool are received. That way, the antibiotic may be changed if there is an indication on the sensitivity results. Instead of finding out the hard way that the antibiotic is not working and then you try to culture the lesion. Run diagnostics first. Complete blood counts, serum biochemical profiles, urinalysis and fecal examinations are the minimum database that I encourage all to use more frequently.

\section{Acknowledgements}

None.

\section{Conflict of interest}

Author declares that there is no conflict of interest.

\section{References}

1. Raskin RE, Meyer D. Canine and Feline Cytology: A Color Atlas and Interpretation Guide. 3rd ed. St. Louis, Missouri: Elsevier; 2016. p. 453-518.

2. Brink AJ, Van Wyk J, Moodley VM, et al. The Role Of Appropriate Diagnostic Testing In Acute Respiratory Tract Infections: An antibiotic stewardship Strategy to minimise diagnostic uncertainty in primary Care. S Afr Med J. 2016;106(6):554-561.

3. Hoffmann-Sommergruber K, Pfeifer S, Bublin M. Applications of Molecular Diagnostic Testing in Food Allergy. Curr Allergy Asthma Rep. 2015;15(9):56.

4. Rollnik J. Outcome of MRSA carriers in neurological early rehabilitation. BMC Neurol. 2014;14:34.

5. Schmid H, Romanos A, Schiffl H, et al. Persistent nasal methicillinresistant staphylococcus aureus carriage in hemodialysis outpatients: a predictor of worse outcome. BMC Nephrology. 2013;14:93.

6. Win MK, Soliman TA, Lee LK, et al. Review of a two-year methicillinresistant Staphylococcus aureus screening program and costeffectiveness analysis in Singapore. BMC Infect Dis. 2015;15:391.

7. Lee AS, Pan A, Harbarth S, et al. Variable performance of models for predicting methicillin-resistant Staphylococcus aureus carriage in European surgical wards. BMC Infect Dis. 2015;15:105. 
8. Batra R, Eziefula AC, Wyncoll D, et al. Throat and rectal swabs may have an important role in MRSA screening of critically ill patients. Intensive Care Med. 2008;34(9):1703-1706.
9. Nowak R. Flesh-eating bacteria: not new, but still worrisome. Science. 1994;264(5166):1665. 